\title{
EFFORTS TO IMPROVE STUDENTS COMMUNICATION SKILLS THROUGH THE APLICATION OF THE TEAM QUIZ LEARNING METHOD
}

\author{
Fulkanis \\ SDN 016 Sako, Pangean, Indonesia \\ fulkanis@yahoo.com
}

\begin{abstract}
This research is motivated the low learning activity carried out by students which still passive so that the lack of student skills, one of which is communication skills. As an effort to improve students communication skills is the aplication of a team quiz. Team quiz can be interpreted as a learning activity carried out in groups to discuss a material that is being studied. This research was conducted in class V SDN 016 Sako, Pangean District, totaling 75 students. The instrument used was the observation of students' communication skills. The results showed that the skills of students in the first cycle were 71.44 which was a good category, in the second cycle it increased to 83.23 in the very good category. Based on the research results, it can be concluded that the application of the team quiz method can improve students' communication skills. Students are able to ask questions and explain answers fluently and use language that is easy to understandably.
\end{abstract}

Keywords: communication skills, team quiz

\section{UPAYA MENINGKATKAN KETERAMPILAN BERKOMUNIKASI SISWA MELALUI PENERAPAN METODE PEMBELAJARAN TEAM QUIZ}

\begin{abstract}
ABSTRAK
Penelitian ini dilatarbelakangi oleh rendahnya aktifitas pembelajaran yang dilakukan siswa masih bersifat pasif sehingga kurangnya keterampilan siswa salahsatunya adalah keterampilan berkomunikasi. Sebagai upaya untuk meningkatkan keterampilan berkomunikasi siswa adalah dengan penerapan team quiz. Team quiz dapat dimaknai sebagai kegiatan pembelajaran yang dilakukan secara berkelompok untuk membahas suatu materi yang sedang dipelajari. Penelitian ini dilaksanakan pada kelas V SDN 016 Sako Kecamatan Pangean yang berjumlah 75 siswa. Instrumen yang digunakan adalah observasi keterampilan berkomunikasi siswa. Hasil penelitian menunjukkan bahwa keterampilan siswa pada siklus I sebesar 71.44 yang merupakan kategori baik, pada siklus II mengalami peningkatan menjadi sebesar 83.23 dengan kategori sangat baik. Berdasarkan hasil penelitian dapat disimpulkan bahwa penerapan metode team quiz dapat meningkatkan keterampilan berkomunikasi siswa. Siswa mampu mengajukan petanyaan dan memberikan penjelasan jawaban dengan lancar dan menggunakan bahasa yang mudah dimengerti.
\end{abstract}

Kata Kunci: keterampilan berkomunikasi, team quiz

\begin{tabular}{|c|c|c|}
\hline Submitted & Accepted & Published \\
\hline 18 Agustus 2020 & 14 September 2020 & 28 September 2020 \\
\hline
\end{tabular}

\begin{tabular}{|l|l|c|ccc|}
\hline Citation & $:$ & $\begin{array}{c}\text { Fulkanis. (2020). Efforts To Improve Students Communication Skills Through The Aplication Of The Team Quiz } \\
\text { Learning Method. Jurnal PAJAR (Pendidikan dan Pengajaran), 4(5), 1040-1045. DOI : } \\
\text { http://dx.doi.org/10.33578/pjr.v4i5.8143. }\end{array}$ \\
\hline
\end{tabular}

\section{PENDAHULUAN}

Kemampuan dan daya pikir yang dimiliki siswa dalam pembelajaran dapat ditingkatkan melalui pendidikan yang dilakukan sekolah melalui peran guru dalam membimbing siswa menemukan dan mengasah kemampuannya dalam berkomunikasi dalam pembelajaran. Kemampuan tersebut baik yang berbentuk ilmu, pengetahuan, teknologi, keterampilan, sikap dan kebijaksanaan dapat dimanfaatkan dalam menghadapi permasalahan yang ada di kehidupannya.
Pendidikan bertujuan untuk membentuk manusia yang mampu berpikir kreatif, kritis, dan inovatif serta komunikatif (Rachmantika, 2019).

Kualitas siswa yang dihasilkan dari sekolah tidak lepas dari berbagai faktor antara lain pengemasan pembelajaran yang tepat bagi permasalahan dan kebutuhan siswa (Adnyana, 2014), kurangnya metode pembelajaran yang dilakukan guru (Tsai, 2012), kurangnya kemampuan komunikasi yang dimiliki siswa yang 
mencerminkan rendahnya kualitas pendidikan khususnya keterampilan berpikir kritis (Panagiotis, 2011).

Fakta di lapangan yang sering dijumpai bahwa kegiatan pembelajaran yang dilakukan selama ini masih menggunakan metode konvensional dimana guru cenderung ceramah dengan menjelaskan materi yang tertera di buku dengan sesekali menuliskannya di papan tulis tanpa adanya bantuan media atau alat peraga yang memudahkan siswa dalam melihat bentuk yang abstrak. Selain itu guru tidak melibatkan siswa melakukan aktifitas belajar, siswa cenderung pasif menerima informasi yang bersumber dari guru tanpa mencari dan menemukan sendiri permasalahan yang mereka hadapi. Dengan kondisi ini, kemampuan komunikasi siswa sulit mengalami peningkatan karena tidak adanya waktu untuk menyampaikan pertanyaan dan penjelasan serta terbatasnya sumber informasi yang mereka peroleh bahkan bisa saja informasi tersebut menjadi salah paham.

Pembelajaran yang memfasilitasi keaktifan siswa dapat menunjang prestasi dan kemampuan yang baik dalam pemahaman siswa terhadap materi terlebih jika melatih keterampilan berkomunikasi, karena melalui proses komunikasi siswa dapat memperoleh informasi yang benar dan tepat, mampu memecahkan masalah, dan memahami suatu konsep secara dalam.

Banyak model dan metode pembelajaran yang dapat memfasilitasi aktifitas siswa dalam mengasah kemampuan komunikasi satu di antaranya adalah pembelajaran tipe team quiz dimana siswa belajar secara berkelompok dan mengasah kemampuan komunikasi melalui diskusi yang dilakukan sesuai arahan guru (Lenggogeni, 2013). Satu penelitian terdahulu yang berhasil meningkatkan keterampilan berkomunikasi melalui pembelajaran tipe team quiz dilakukan oleh Purnama (2016).

\section{KAJIAN TEORETIS}

\section{Keterampilan Berkomunikasi}

Komunikasi dapat diartikan sebagai sarana menampilkan pesan, mengekspresikan diri, serta mempengaruhi orang lain (Marfuah, 2017).
Komunikasi juga diartikan sebagai pengalihan pesan baik secara lisan maupun tulisan. Proses pembelajaran berjalan baik jika ada komunikasi karena komunikasi merupakan jantung terjadinya interaksi dalam pembelajaran (Iriantara dalam Maisyarah, 2017). Dapat ditarik kesimpulan bahwa komunikasi adalah cara yang dilakukan untuk menyampaikan pesan berupa lisan maupun tulisan yang dapat mempengaruhi orang lain dalam bentuk pengetahuan maupun tindakan.

Siswa diharapkan mampu melakukan komunikasi dengan baik. Keterampilan ini diupayakan hadir dengan adanya respon siswa terhadap kegiatan pembelajaran yang dilakukan berupa adanya upaya untuk mengajukan pertanyaan untuk menambah pengetahuan dan berupaya memberikan penjelasan yang mudah dipahami oleh siswa lain.

Indikator keterampilan berkomunikasi yang digunakan dalam penelitian ini adalah sebagai berikut: 1) Menjelaskan ide, situasi, dan relasi IPA secara tulisan dengan benda nyata, gambar, atau grafik. 2) Menghubungkan benda nyata, gambar atau diagram ke dalam IPA. 3) Menyatakan peristiwa sehari-hari dalam bahasa atau simbol IPA

\section{Metode Pembelajaran Team Quiz}

Pembelajaran team quiz berupa melakukan diskusi terhadap materi yang dipelajari, memberikan arahan, mengajukan pertanyaan dan memberikan jawaban atas pertanyaan yang diajukan (Wahyudi, 2018). Metode ini digunakan untuk menggerakkan diskusi serta meningkatkan kemampuan siswa dalam menentukan, menilai, dan memecahkan masalah yang dihadapi dalam kehidupannya dengan cara yang bersahabat dan menarik (Tampubolon, 2013). Jadi team quiz merupakan kegiatan pembelajaran berupa diskusi berkelompok yang dapat meningkatkan kemampuan siswa dalam menentukan, menilai dan memecahkan masalah yang dihadapi dengan cara yang menyenangkan. Melalui pembelajaran ini siswa menjadi termotivasi dalam melakukan pembelajaran (Tulsahidah, 2018) (Sulistyowati, 2018) (Zainuddin, 2015). Pada akhirnya jika 
dioptimalkan dengan baik maka prestasi belajar siswa menjadi meningkat (Mahendra, 2015).

Prosedur pembelajaran team quiz adalah sebagai berikut (Suprijono, 2014): 1) Guru menentukan topik untuk dipilih 3 kelompok siswa agar dipresentasikan dalam pelaksanaan pembelajaran. 2) Siswa terbagi dalam 3 kelompok yang diberi nama A, B, dan C. 3) Guru menjelaskan format pembelajaran, dan meminta siswa melakukan persentasi masing-masing 10 menit. 4) Kelompok A presentasi, kelompok B menyimak dan bersiap melakukan tanya jawab dengan kelompok A. 5) Kelompok A mengajukan pertanyaan pada kelompok B, jika tanpa ada jawaban yang tepat maka bisa diajukan pada kelompok C. demikian sebaliknya jika pertanyaan diajukan pada kelompok $\mathrm{C}$ dan tidak menemukan jawaban yang tepat maka dilemparkan pada kelompok B. 6) Kegiatan yang sama juga dilakukan oleh kelompok B dan C.Setelah semua kelompok telah melakukan tugasnya maka secara bersama-sama menarik kesimpulan dari hasil diskusi yang telah disepakati jawaban dan temuannya.

\section{METODE PENELITIAN}

Metode yang digunakan dalam penelitian ini adalah penelitian tindakan kelas (Arikunto, 2006) dengan tindakan berupa penggunaan metode team quiz. Metode ini diharapkan mampu meningkatkan keterampilan berkomunikasi siswa dalam pelajaran IPA materi gaya. Materi gaya memiliki banyak bahasan sehingga cocok untuk dilakukan pembelajaran team quiz yang melibatkan banyak siswa. Materi yang banyak dapat dapat dibahas dengan utuh karena banyak siswa yang dapat mempelajarinya dengan pembagian tugas atau bahasan sehingga saat dipelajari dengan metode team quiz sangat optimal karena semua siswa dapat bertanya dan memberikan pendapat berdasarkan pengetahuan yang mereka miliki.

Pelaksanaan penelitian ini di SDN 016 Sako Kecamatan Pangean pada siswa kelas V. subjek penelitian berjumlah 74 orang siswa dengan laki-laki sebanyak 49 dan perempuan 26 siswa. Masing-masing siswa dibagi kedalam 3 kelompok yang berisikan 25 orang siswa. Penelitian ini dilaksanakan pada semester genap bulan januari sampai februari 2020.

\section{Teknik Pengumpulan dan Pengolahan Data}

Data dikumpulkan dengan teknik observasi yang dibantu oleh observer dalam mengamati kegiatan siswa dalam melakukan komunikasi dalam pembelajaran. Dari hasil pengamatan dapat diketahui sejauh mana pelaksanaan dan keberhasilan yang dicapai dalam pembelajaran sehingga dapat dijadikan sebagai bahan untuk tindaklanjut pada tahap berikutnya. Jika hasil sudah memenuhi indikator yang ditetapkan maka penelitian dianggap sudah berhasil atau tercapai. Teknik ini digunakan untuk mengetahui sejauh mana keaktifan siswa serta peningkatan kemampuan komunikasi siswa yang diterapkan metode pembelajaran team quiz.

Setelah data dikumpulkan, selanjutnya data diolah dengan melakukan analisis kualitatif deskriptif. Analisis data observasi siswa dapat menggunakan rumus berikut (Agip, 2009):

$$
\text { skor akhir }=\frac{\text { skor perolehan siswa }}{\text { skor maksimal }} \times 100 \%
$$

Setelah diperoleh hasil observasi keterampilan berkomunikasi siswa maka dilakukan kategorisasi sebagai berikut:

Tabel. 1 Kategori Keterampilan Berkomunikasi

\begin{tabular}{cc}
\hline Skala (\%) & Kategori \\
\hline $81-100$ & Sangat Baik \\
$71-80$ & Baik \\
$56-70$ & Cukup \\
\hline
\end{tabular}




\begin{tabular}{cc}
\hline $41-55$ & Kurang \\
$<40$ & Sangat Kurang \\
\hline
\end{tabular}

Peneliti berharap kemampuan berkomunikasi siswa mencapai kategori sangat baik atau minimal skor perolehan siswa sebesar $81 \%$.

\section{HASIL DAN PEMBAHASAN}

Hasil pengamatan

keterampilan berkomunikasi siswa pada siklus I dan II disajikan pada gambar berikut:

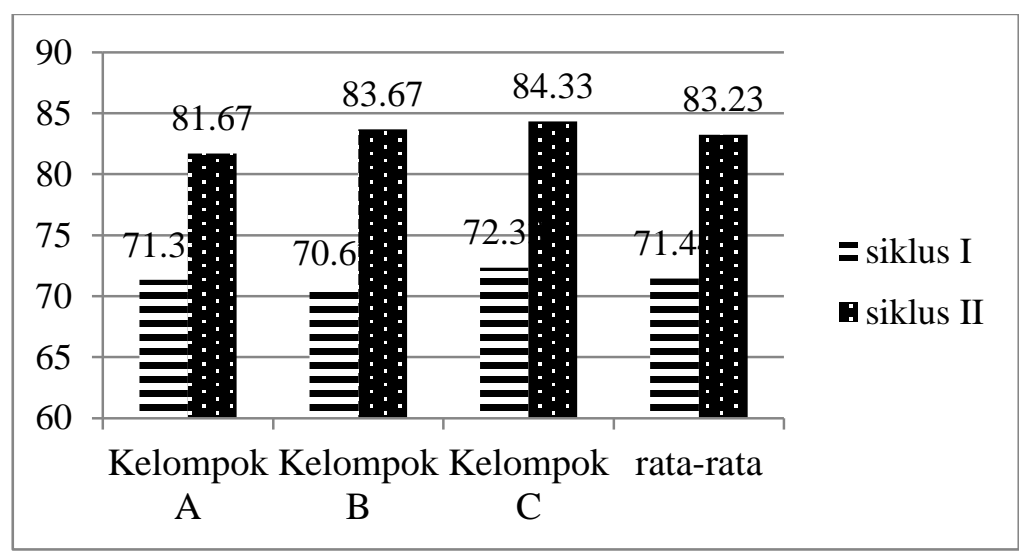

Gambar 1. Persentase Keterampilan Berkomunikasi Siswa

Gambar 1 menunjukkan bahwa rata-rata keterampilan berkomunikasi siswa pada siklus I adalah sebesar 71.44 dengan kategori baik. Peneliti membagi penilaian sesuai kelompok dimana kelompok A memperoleh nilai rata-rata sebesar 71.33 yang termasuk baik, kelompok B sebesar 70.67 dengan kategori cukup, dan kelompok C dengan rata-rata 72.33 yang termasuk kategori baik. Masing-masing kelompok berupaya untuk melakukan yang terbaik dengan kerja sama dalam mencari jawaban atas pertanyaan yang diajukan. Hal ini menunjukkan bahwa team quiz dapat meningkatkan kemampuan kerja sama antar siswa (Marcella, Wulanata, dan Listiani, 2018).

Pada siklus II guru meminta setiap siswa berupaya aktif dalam pembelajaran dengan membaca buku atau sumber belajar lainnya untuk mengajukan pertanyaan terkait materi yang dipelajari, sehingga dengan pengetahuan yang dimiliki siswa terjadi peningkatan aktifitas Tanya jawab antar siswa. Selain itu tampak bahwa kualitas pertanyaan cukup baik. Terlihat keterampilan siswa dalam berpikir lebih kritis dengan adanya team quiz yang dilakukan mengalami peningkatan (Fadhila, 2016). Peningkatan yang terjadi pada siklus II adalah mencapai rata-rata sebesar 83.23, nilai ini masuk dalam kategori sangat baik. Secara detil keterampilan siswa kelompok A sebesar 81.67, kelompok B 83.67, dan kelompok C 84.33.

Hasil ini menggambarkan bahwa pencapaian ini telah memenuhi indikator keberhasilan yang diharapkan yakni masuk dalam kategori sangat baik. Ini menandakan bahwa penerapan metode pembelajaran team quiz dapat meningkatkan keterampilan berkomunikasi siswa. Siswa tidak hanya menerima informasi namun menggali informasi dari berbagai sumber dan proses tanya jawab yang dilakukan antar siswa satu sama lain yang diwadahi dalam kelompok. Siswa lebih aktif dan bisa bekerjasama dalam 
memecahkan masalah melalui diskusi (Junaidi, dan Taufik, 2020).

\section{Pembasahasan}

Keterampilan siswa pada siklus I baik, dimana beberapa siswa terlihat aktif dalam proses diskusi yang dilakukan. Masing-masing kelompok mampu mengajukan pertanyaan dan jawaban yang baik terkait materi yang dibahas. Misal kelompok A bertanya "apa saja contoh gaya dalam kegiatan sehari-hari?" kemudian dijawab oleh kelompok B "contohnya adalah menyetrika pakaian (gaya gesek), mendorong meja (gaya dorong)" dan ditambahkan oleh kelompok C "mengangkat tas (gaya otot), pensil jatuh (gaya gravitasi). Bertanya dan mengajukan pertanyaan merupakan pokok bahasa komunikasi, selain itu juga mengungkapkan perasaan, memberikan alasan, dan mempertegas pendapat (Royani, 2014).

Pada siklus II siswa lebih aktif dalam melakukan kegiatan pembelajaran karena masingmasing siswa diminta untuk memberikan tanggapan baik berupa pertanyaan maupun jawaban atau materi yang sedang dibahas. Siswa berusaha menyampaikan pengetahuan yang mereka miliki pada siswa lain dan memberikan penguatan atau sanggahan jika ada pernyataan yang kurang sependapat. Dengan adanya metode ini siswa mampu berargumen dengan baik dan benar dan dapat memperoleh kebenaran dari hasil diskusi melalui team quiz yang mereka lakukan. Karena melalui team quiz siswa mampu menjelaskan jawaban dengan lancar dan bahasa yang mudah dimengerti (Lovenidiana, 2014).

\section{SIMPULAN DAN REKOMENDASI}

Berdasarkan hasil penelitian tersebut dapat disimpulkan bahwa penerapan metode team quiz dapat meningkatkan keterampilan berkomunikasi siswa kelas V SDN 016 Sako Kecamatan Pangean dengan rata-rata keterampilan berkomunikasi pada siklus I sebesar 71.44 dengan kategori baik menjadi meningkat pada siklus II sebesar 83.23 dengan kategori sangat baik. Siswa mampu mengajukan pertanyaan yang baik serta mampu memberikan penjelasan dengan lancar menggunakan bahasa yang mudah dipahami oleh siswa lain.
Rekomendasi berdasarkan hasil penelitian adalah agar guru dapat mengatur jalannya team quiz sehingga terjadi interaksi dan secara merata siswa melakukan kegiatan pembelajaran, tidak hanya siswa pintar yang aktif dalam pembelajaran. Selain itu agar siswa lebih termotivasi ada baiknya guru memberikan reward bagi siswa ataupun kelompok yang unggul dalam proses pembelajaran sehingga siswa saling berkompetisi menjadi yang terbaik.

\section{DAFTAR PUSTAKA}

Adnyana, M, E., Ristiati, N, P., dan Setiawan, I, G, A, N. (2014). Pengaruh Model Pembelajaran Teams Games Tournament Universitas Pendidikan Ganesha Singaraja Indonesia. e-Journal Program Pascasarjana Universitas Ganesha, 4 (2).

Agip, Z, dkk. (2009). Penelitian Tindakan Kelas untuk Guru SD, SLB, dan TK. Bandung: Yrama Widya, 41

Arikunto, S. (2006). Penelitian Tindakan Kelas. Jakarta: Bumi Aksara.

Fadhila. (2016). Peranan Strategi Pembelajaran Aktif Tipe Tim Quiz (Quiz Team) Terhadap Kemampuan Berpikir Kritis Siswa pada Pembelajaran Siswa Kelas XI IPA MAN Pol-Man Kabupaten Polewali Mandar. Jurnal Saintifik, 2 (2), 105-114.

Junaidi., \& Taufik. (2020). Penerapan Model Pembelajaran Active Learning Team Quiz untuk Meningkatkan Kemampuan Komunikasi Matematissiswa SMP. Jurnal Sosial Humaniora Sigli, 3 (1), 13-18.

Lenggogeni, P., Neolaka, A., dan Saleh, R. (2013). Perbedaan Metode Pembelajaran Aktif Tipe Quiz Team dengan Metode Konvensional Plus Terhadap Hasil Belajar Ilmu Konstruksi Bangunan (Eksperimen Pada Siswa Kelas X TGB SMKN 1 Jakarta). Jurnal Pensil Jurusan Teknik Sipil Ft Unj, 2 (2), 94-110.

Lovenidiana, R, A., dan Rahaju, E, B. (2014). Kemampuan Komunikasi Matematika Siswa Pada Penerapan Pembelajaran Aktif Strategi Team Quiz Materi Statistika. MATHEdunesa: Jurnal Ilmiah Pendidikan Matematika, 3 (3), 202-207. 
Mahendra, G. (2015). Optimalisasi Penggunaan Metode Quiz Team dalam Model Pembelajaran Kuantum untuk Meningkatkan Prestasi Belajar Pkn Siswa. DAIWI WIDYA: Jurnal Pendidikan, 2 (2), $1-13$.

Maisyarah. (2017). Meningkatkan Kemampuan Komunikasi Matematis Peserta Didik Menggunakan Model Pembelajaran Kooperatif Tipe STAD di Kelas XII IPS. EDU-MAT Jurnal Pendidikan Matematika, 5 (1), 76-85.

Marcella, A., Wulanata, I, A., dan Listiani, T. (2018). Penerapan Team Quiz untuk meningkatkan Kemampuan Kerja Sama Antar Siswa Kelas VIII-B pada Mata Pelajaran Matematika. JOHME: Journal of Holistic Mathematics Education, 1(2), 124.

Marfuah. (2017). Meningkatkan Keterampilan Komunikasi Peserta Didik Melalui Model Pembelajaran Kooperatif Tipe Jigsaw. Jurnal Pendidikan Ilmu Sosial, 26 (2), $148-160$

Panagiotis, K., dan Saariluoma, P. E. B. (2011). Fostering Creative Thinking. Journal, Hellenic, (1), 46-64.

Purnama, I, L., dan Afriansyah, E, A. (2016). Kemampuan Komunikasi Matematis Siswa Ditinjau Melalui Model Pembelajaran Kooperatif Tipe Complete Sentence dan Team Quiz. Jurnal Pendidikan Matematika, 10 (1), 26-42.

Rachmantika, A, S., dan Wardono. (2019). Peran Kemampuan Berpikir Kritis Siswa pada Pembelajaran Matematika dengan Pemecahan Masalah. PRISMA: Prosiding Seminar Nasional Matematika, (2) 439443.

Royani , M., B. M. (2014). Keterampilan Bertanya Siswa SMP Melalui Strategi Pembelajaran Aktif Tipe Team Quiz pada Materi Segi Empat. EDU-MAT Jurnal Pendidikan Matematika, 2 (1), 22-28.

Sulistyowati, A. (2018). Penerapan Model Pembelajaran Quiz Team Untuk Meningkatkan Motivasi dan Hasil Belajar Materi Pemerintah Kabupaten dan Kota
Pada Siswa Kelas IV SD 4 Kaliwungu. Jurnal Prakarsa Paedagogia, 1 (2), 144151.

Tampubolon, R, J. (2013). Pengaruh Penggunaan Metode Quiz Team Terhadap Kemampuan Menentukan Unsur Instrinsik Cerpen Siswa Kelas X SMA Negeri 1 Saipar Dolok Hole Tahun Pembelajaran 2013/2014. Asas: Jurnal Sastra, 2 (2).

Tsai, K. C. (2012). Dance with Critical Thinking and Creative Thinking in the Classroom. Journal of Sociological Research, 3 (2), 312-324.

Tulsahidah, R. (2018). Penerapan Metode Pembelajaran Team Quiz dalam Meningkatkan Motivasi dan Hasil Belajar Kognitif Peserta Didik Pada Mata Pelajaran Fiqih Materi Makanan dan Minuman Halal dan Haram. Atthulab: Islamic Religion Teaching And Learning Journal, 3 (1), 22-42.

Wahyudi, M, A. (2018). Pengaruh Strategi Team Quiz dalam Meningkatkan Pemahaman Teks Bahasa Inggris pada Semester Lima Jurusan Bahasa Inggris di STKIP PGRI Bangkalan. Wacana Didaktika: Jurnal Pemikiran, Penelitian Pendidikan dan Sains, 6 (2), 164-170.

Zainuddi. (2015). Efektivitas Model Pembelajaran Kooperatif Tipe Team Quiz Berbantuan Macromedia Flash Terhadap Hasil Belajar Siswa Materi Kubus dan Balok Kelas VIII. DELTA: Jurnal Ilmiah Pendidikan Matematika, 3 (2), 65-73. 